\title{
Recent advances in primary percutaneous intervention for acute myocardial infarction
}

\author{
E J Smith, A Mathur, M T Rothman
}

Heart 2005;91:1533-1536. doi: 10.1136/hrt.2005.064493

\begin{abstract}
nterventional cardiology has evolved since the first studies comparing primary percutaneous intervention (PPCI) and intravenous thrombolysis for the treatment of ST segment elevation myocardial infarction (STEMI). Indeed it may now seem remarkable that in an era where abrupt vessel closure and restenosis occurred routinely in up to $8 \%$ and $40 \%$, respectively, ${ }^{12}$ plain balloon angioplasty was able to demonstrate significant improvements in short and long term outcome relative to thrombolysis. ${ }^{34}$ This emphasises the prognostic importance of restoring effective flow in the culprit vessel as early as possible, for which PPCI has been highly effective from the outset. However, the corollary is that despite major advances in stent technology and adjuvant pharmacology since that time, the absolute outcome benefits of PPCI remain definite but modest. ${ }^{5}$ Here we put into context some of the recent advances in the field of PPCI, highlighting key questions that are yet to be answered, and speculate on what the future may offer as this therapy secures its place as the preferred treatment strategy for STEMI.
\end{abstract}

\section{OPTIMISING REPERFUSION}

As we consider how best to optimise our approach to reperfusion, it becomes clear that the traditional debate between mechanical and pharmacological strategies is over simplistic. While it is essential to deliver reperfusion therapy as early as possible following medical contact, even prompt delivery of thrombolysis necessitates a back up PCI strategy for patients with recurrent ischaemia or failure to reperfuse. The CAPTIM study ${ }^{6}$ highlighted this issue, with $70 \%$ of patients randomised to pre-hospital thrombolysis undergoing a PCI by 30 days. Meanwhile PPCI itself necessitates the use of antiplatelet and antithrombotic therapies, with a minimum combination of aspirin, a theinopyridine (clopidogrel), and heparin. Platelet glycoprotein IIb/IIIa receptor antagonists (GpRAs) are also associated with improved clinical outcomes in the setting of PPCI, with early delivery before the procedure improving the rate of epicardial patency at angiography, and conferring additional benefit. ${ }^{7}$ Restoration of epicardial flow before the start of intervention is certainly associated with superior outcomes following PPCI, ${ }^{8}$ and in this symposium Brodie has already discussed the facilitated approach with antecedent GpRAs, thrombolytic agents, or combined therapy. ${ }^{9}$

Also in this symposium Prasad and Gersh have further emphasised the importance of looking beyond the epicardial vessel, to the microcirculation, in order to optimise outcomes. ${ }^{10}$ Indeed, the clinical benefits of GpRAs may be partly mediated by improved microvascular perfusion. This has been demonstrated in studies employing angiographic perfusion scores, invasive measurement of coronary flow, and myocardial contrast echocardiography. ${ }^{11}{ }^{12}$ GpRAs may reduce distal microemboli, and the formation of platelet microparticles that can be deleterious to the microvasculature, though anti-inflammatory mechanisms may also be relevant. However, more recent data have been less supportive of this concept, ${ }^{13}$ and importantly there is as yet no gold standard method to measure microvascular dysfunction following PPCI. Furthermore, other pharmacological interventions deliberately directed against microvascular dysfunction, including administration of intracoronary adenosine and nicorandil, have made little impact on routine clinical practice. ${ }^{14} 15$

In an attempt to limit the impact of procedurally related distal embolisation, mechanical distal protection and thrombectomy devices have been developed though their role in the setting of STEMI is not yet clearly defined. While they have the potential to prevent deterioration in microvascular perfusion, none have yet delivered an improvement in clinical outcome. In the EMERALD (enhanced myocardial efficacy and recovery by aspiration of liberalized debris) study the PercuSurge GuardWire distal protection system (Medtronic, Santa Rosa, California, USA) used during PPCI less than six hours after presentation with STEMI did not improve angiographic perfusion scores, ST segment resolution, final infarct size, or clinical end points when compared to the results from a randomised control group. ${ }^{16}$ Perhaps more surprising are the results of the recently presented AIMI study ${ }^{17}$ where rheolytic thrombectomy (Angiojet, Possis) not only failed to improve the quality of reperfusion (despite a prior supportive study $^{18}$ ), but was also associated with a significant increase in mortality when compared with routine PPCI alone. A number of explanations could account for these disappointing results. Pathophysiologically, removal of thrombus from the epicardial portion of the infarct vessel may not be sufficient to improve microvascular dysfunction-a process that is also influenced by ischaemic endothelial damage, myocardial oedema, platelet and leucocyte interactions, and the release of soluble factors. However, the design of both studies may be relevant. Neither study specifically targeted patients with angiographically evident thrombus, a study design which may have been more intuitive. In addition, these studies may simply be looking at the wrong clinical outcomes. Non-fatal myocardial infarction (NFMI) and recurrent ischaemia are more likely determined by plaque instability than microvascular perfusion while prognosis following STEMI is determined predominantly by left ventricular (LV) function.

Symptom duration may have a critical influence in determining the success of thrombus removal, distal embolisation prevention, and the ability to achieve microvascular

Abbreviations: $A M I$, acute myocardial infarction; BMS, bare metal stents; BMSC, bone marrow stem cell; DES, drug eluting stent;

EMERALD, enhanced myocardial efficacy and recovery by aspiration of liberalized debris; EPC, endothelial progenitor cell; GPRA, glycoprotein Ilb/Illa receptor antagonist; ISR, in-stent restenosis; IVUS, intravascular ultrasound; LV, left ventricular; NFMI, non-fatal myocardial infarction; $\mathrm{PPCl}$, primary percutaneous coronary intervention; SES, sirolimus eluting stent; STEMI, ST elevation myocardial infarction; TIMI, thrombolysis in myocardial infarction 
patency such as to maintain or restore significant LV function or to prevent the damage occurring. It is likely that microvascular injury (and thrombus burden) are maximal in patients presenting beyond the first 2-4 hours, by which time the percentage of "at risk" myocardium amenable to salvage may have already fallen significantly. It is true that interventions aimed solely at achieving good (TIMI grade 3 ) epicardial flow may be failing to address the whole problem. However, because it is difficult to assess small changes in LV function it may be difficult to prove that a benefit has been achieved by interventions targeting the microvasculature. Even using the most accurate techniques (for example, magnetic resonance imaging, three dimensional echocardiography), we may not be able to demonstrate an improvement that translates into a prognostic benefit. Symptomatic outcomes (for example, New York Heart Association class, readmissions with heart failure) could prove more relevant, particularly for patients presenting late. In addition, factors such as oxygenation or collateral supply may influence our ability to achieve LV salvage and will vary considerably between individual patients.

Our own perspective is that these devices are extremely valuable in selected cases with clear angiographic thrombus. However, while the present lack of measurable benefit of these devices for STEMI may simply be a consequence of patient selection or our inability as yet to define the correct parameter for measurement to assess outcome, taken together these data could lead us to question whether PPCI has already reached a limit in terms of its ability to restore optimal blood flow. If so, what more can PPCI offer beyond reperfusion?

\section{PLAQUE STABILISATION}

PPCI allows the cardiologist direct access to an acutely destabilised plaque. As in elective PCI, coronary stenting for STEMI reduces abrupt vessel closure and restenosis. ${ }^{19} 20$ However, it is also possible that by restoring luminal laminar flow $^{21} 22$ and encouraging healing of the ruptured plaque by early re-endothelialisation that plaque stability is promoted..$^{23}$ This effect may be over and above the influence of systemic therapy (principally with oral statins, and angiotensin converting enzyme inhibitors). Furthermore these plaque stabilisation manoeuvres may contribute to the reduction in recurrent events observed following PPCI relative to thrombolysis. Paradoxically, the in-stent healing process that is often benign, and indeed essential, may in some cases be exaggerated and lead to the development of symptomatic instent restenosis (ISR). What then is the role of the drug eluting stent (DES) in the prevention of ISR in the acute myocardial infarction (AMI) patient?

At present the available technologies target prevention of ISR with antiproliferative coatings (for example, paclitaxel and sirolimus). These agents impair endothelial healing, and therefore present a theoretical disadvantage in the setting of STEMI that could manifest as recurrent events, particularly subacute thrombosis. In practice, registry data confirm that sirolimus eluting stent (SES) implantation is associated with similar rates of death and NFMI compared with bare metal stents (BMS) out to 300 days following STEMI, with a significant reduction in target vessel revascularisation $(8.2 \%$ BMS $v 1.1 \%$ SES; $\mathrm{p}<0.01) .{ }^{24}$ Nonetheless, longer follow up and randomised controlled studies will be needed to assuage concerns regarding late thrombosis occurring beyond 12 months. ${ }^{25}$

An alternative drug elution strategy for STEMI is to target the destabilised plaque specifically. Local anti-inflammatory therapy via a dexamethasone eluting stent (Dexamet, Abbott Vascular) appeared to preferentially reduce restenosis in acute coronary syndrome patients compared to stable patients, with similar late lumen loss when compared to antiproliferative agents in a non-randomised registry. ${ }^{26}$ This supports the notion that the restenotic response is itself modified in the setting of plaque instability with a greater inflammatory component. More recently local drug delivery has attempted acceleration of endothelialisation as a means of preventing ISR. Recruitment and binding of circulating endothelial progenitor cells (EPCs) using a dextran coated stent embedded with CD34 antibody (Orbus Medical Technologies, Fort Lauderdale, Florida, USA) is one of a number of pro-endothelialisation approaches, and is designed to enable formation of a complete biologically active mature endothelial monolayer by 72 hours following stent implantation. If successful, this mechanism in particular could be ideally placed to heal and stabilise an acutely ruptured plaque in the setting of AMI. Other pro-endothelial candidates include local oestradiol delivery, and local nitric oxide releasing coatings. These developments are in their early stages, but demonstrate the potential for a STEMI specific approach in the future.

In addition to treating the already ruptured culprit plaque, PPCI offers the opportunity to identify other high risk "vulnerable" lesions at the same time. Angiographic, ${ }^{27}$ angioscopic, ${ }^{28}$ and intravascular ultrasound (IVUS) ${ }^{29}$ studies have already established that multiple complex plaques coexist throughout the coronary tree in patients presenting with STEMI, though there is still debate as to their prognostic importance. ${ }^{27} 290$ Advanced IVUS analysis of plaque morphology (using elastography, ${ }^{31}$ virtual histology ${ }^{32}$ ) may enable selection of additional "at risk" non-culprit lesions, and should ongoing studies provide a positive answer to this debate, then stabilisation with PCI or additional systemic therapeutic strategies may be indicated.

\section{MYOCARDIAL REGENERATION}

While prompt reperfusion in patients presenting early has the ability to abolish myocardial necrosis, what should be done for those presenting late with "irreversible" myocardial damage? For these patients the ultimate goal is the repair and regeneration of the damaged myocardium. The demonstration by Orlic et $a l^{33}$ that transplanted bone marrow stem cells (BMSCs) can migrate into infarcted mouse myocardium resulting in vascular and myocyte proliferation has been followed by a series of small clinical studies investigating stem cell suspensions for myocardial regeneration following STEMI.

Three trials have already demonstrated improvements in left ventricular function following BMSC therapy ${ }^{34-36}$ (table $1^{37}$ ). These protocols involved the delayed (by several days) infusion of autologous cells via the infarct related artery. Whether this beneficial response may be time dependent remains to be seen, and studies are underway examining "early - same day" BMSC administration via the epicardial infarct related vessel. Importantly, however, recent data from a rat model of infarction suggest that arterial patency is a prerequisite for functional myocardial improvement following stem cell infusion (A Mathur, personal communication). The challenge of the patient without a patent infarct related vessel, necessitating local administration of BMSCs, is still an issue and retrograde coronary venous injection or direct administration to the infarcted or peri-infarcted muscle are feasible but are significant procedural undertakings. The results of the studies to date can be greeted with cautious optimism. Important questions remain as to the mechanism of LV improvement. The early view was that BMSC's transdifferentiated into new cardiomyocytes, but this appears unlikely, with emerging evidence suggesting that the improvements observed may be mediated by new vessel formation (angiogenesis) in the infarct zone. ${ }^{38}$ 
Table 1 Comparison of outcomes of clinical trials of infusion of autologous bone marrow derived progenitor cells following acute myocardial infarction.

\begin{tabular}{|c|c|c|c|c|c|c|c|}
\hline Study & LVEF method & No days after PPCI & $\mathrm{n}$ & LVEF pre & LVEF post & dEF & p Value \\
\hline Assmus et $a f^{\beta 4}$ & Ventriculography & $4.3(1.5)$ & $\begin{array}{l}20 \text { Control } \\
20 \text { BMSC }\end{array}$ & $\begin{array}{l}51 \%(10) \\
51.6 \%(9.6)\end{array}$ & $\begin{array}{l}53.3 \%(7.9) \\
60.1 \%(8.6)\end{array}$ & $\begin{array}{l}2.3 \% \\
8.5 \%\end{array}$ & $\begin{array}{l}\text { NS } \\
0.003\end{array}$ \\
\hline Straver et $a^{\beta 5}$ & Ventriculography & 5.9 & $\begin{array}{l}10 \text { Control } \\
10 \mathrm{BMSC}\end{array}$ & $\begin{array}{l}60 \%(7) \\
57 \%(8)\end{array}$ & $\begin{array}{l}64 \%(7) \\
62 \%(10)\end{array}$ & $\begin{array}{l}4.0 \% \\
5.0 \%\end{array}$ & \\
\hline Wollert et $a \beta^{\beta 6}$ & MRI & $4.8(1.3)$ & $\begin{array}{l}30 \text { Control } \\
30 \text { BMSC }\end{array}$ & $\begin{array}{l}51.3 \%(9.3) \\
50 \%(10)\end{array}$ & $\begin{array}{l}52 \%(12.4) \\
56.7 \%(12.5)\end{array}$ & $\begin{array}{l}0.7 \% \\
6.7 \%\end{array}$ & $\begin{array}{l}\text { NS } \\
0.0026\end{array}$ \\
\hline
\end{tabular}

Adapted from Mathur and Martin ${ }^{37}$ with permission.

BMSC, bone marrow stem cell; LVEF, left ventricular ejection fraction; MRI, magnetic resonance imaging; PPCI, primary percutaneous coronary intervention.

Irrespective of the precise mechanisms, these improvements in LV function appear real, though larger randomised controlled studies are necessary to establish fully the role of this therapy in routine clinical practice, the route of administration, the timing, the need for adjunctive therapies, and to ascertain whether in selected patients this approach may improve prognosis.

\section{BACK TO REALITY}

This futuristic view of PPCI as a triumvirate of reperfusion, plaque stabilisation, and myocardial repair is appealing, and may be realistic within a few years. However, today's reality is that the vast majority of patients in developed countries do not have access to PPCI, and more importantly almost a third of AMI patients receive no reperfusion therapy at all. ${ }^{40}$ Therefore, arguably the most powerful advance in the field of infarct angioplasty has been the demonstration that this treatment can truly be delivered safely, effectively, and in a timely manner to the majority of STEMI patients. Streamlining the service, perhaps with the paramedic team delivering the earliest anticoagulant or antiplatelet treatment, may further benefit the patient destined to receive PPCI. A number of service delivery models have been proposed that can be tailored to suit all but the most remote populations. Whether by adopting a regional heart attack centre model, or by performing local hospital PPCI with off-site surgical cover, benefits can be demonstrated..$^{41-43}$ Therefore the real challenge we face as health providers today is to set up systems of care within hospital networks, crossing traditional geographical and organisational boundaries, in order that the potential rewards we have highlighted here are realised by the majority of heart attack patients tomorrow.

\section{Authors' affiliations}

E J Smith, A Mathur, M T Rothman, London Chest Hospital, London, UK

Correspondence to: Professor Martin T Rothman, Cardiac Research Office, London Chest Hospital, Bonner Road, London E2 9JX, UK; martin.rothman@bartsandthelondon.nhs.uk

\section{REFERENCES}

Fischman DL, Leon MB, Baim DS, et al. A randomized comparison of coronary-stent placement and balloon angioplasty in the treatment of coronary artery disease. Stent restenosis study investigators. N Engl J Med 1994;331:496-501.

2 Lincoff AM, Popma JJ, Ellis SG, et al. Abrupt vessel closure complicating coronary angioplasty: clinical, angiographic and therapeutic profile. J Am Coll Cardiol 1992; 19:926-35.

3 Weaver WD, Simes RJ, Betriu A, et al. Comparison of primary coronary angioplasty and intravenous thrombolytic therapy for acute myocardial infarction: a quantitative review. JAMA 1997;278:2093-8.

4 Zijlstra F, Hoorntje JC, de Boer MJ, et al. Long-term benefit of primary angioplasty as compared with thrombolytic therapy for acute myocardial infarction. N Engl J Med 1999;341:1413-9.

5 Keeley EC, Boura JA, Grines CL. Primary angioplasty versus intravenous thrombolytic therapy for acute myocardial infarction: a quantitative review of 23 randomised trials. Lancet 2003;361:13-20.
6 Bonnefoy E, Lapostolle F, Leizorovicz A, et al. Primary angioplasty versus prehospital fibrinolysis in acute myocardial infarction: a randomised study. Lancet 2002;360:825-9.

7 Montalescot G, Barragan P, Wittenberg O, et al. Platelet glycoprotein Ilb/Illa inhibition with coronary stenting for acute myocardial infarction. N Engl J Med 2001;344:1895-903.

8 Stone GW, Cox D, Garcia E, et al. Normal flow (TIMI-3) before mechanical reperfusion therapy is an independent determinant of survival in acute myocardial infarction: analysis from the primary angioplasty in myocardial infarction trials. Circulation 2001;104:636-41.

9 Brodie BR. Facilitated primary percutaneous intervention. Heart 2005:91:1527-9.

10 Prasad A, Gersh BJ. Management of microvascular dysfunction and reperfusion injury. Heart 2005;91:1530-2.

11 Neumann FJ, Blasini R, Schmitt C, et al. Effect of glycoprotein Ilb/Illa receptor blockade on recovery of coronary flow and left ventricular function after the placement of coronary-artery stents in acute myocardial infarction. Circulation 1998;98:2695-701

12 Petronio AS, Rovai D, Musumeci G, et al. Effects of abciximab on microvascular integrity and left ventricular functional recovery in patients with acute infarction treated by primary coronary angioplasty. Eur Heart $J$ 2003;24:67-76.

13 Costantini CO, Stone GW, Mehran R, et al. Frequency, correlates, and clinical implications of myocardial perfusion after primary angioplasty and stenting, with and without glycoprotein Ilb/Illa inhibition, in acute myocardial infarction. J Am Coll Cardiol 2004;44:305-12.

14 Lim SY, Bae EH, Jeong MH, et al. Effect of combined intracoronary adenosine and nicorandil on no-reflow phenomenon during percutaneous coronary intervention. Circ J 2004;68:928-32.

15 Marzilli M, Orsini E, Marraccini P, et al. Beneficial effects of intracoronary adenosine as an adjunct to primary angioplasty in acute myocardial infarction. Circulation 2000;101:2154-9.

16 Stone GW, Webb J, Cox DA, et al. Distal microcirculatory protection during percutaneous coronary intervention in acute ST-segment elevation myocardial infarction: a randomized controlled trial. JAMA 2005;293:1063-72.

17 Ali A. AngioJet rheolytic thrombectomy in patients undergoing primary angioplasty for acute myocardial infarction (AIMI study). Transcatheter Therapeutics 2004; tctmd.com.

18 Antoniucci D, Valenti R, Migliorini A, et al. Comparison of rheolytic thrombectomy before direct infarct artery stenting versus direct stenting alone in patients undergoing percutaneous coronary intervention for acute myocardial infarction. Am J Cardiol 2004;93:1033-5.

19 Grines CL, Cox DA, Stone GW, et al. Coronary angioplasty with or without stent implantation for acute myocardial infarction. Stent primary angioplasty in myocardial infarction study group. N Engl J Med 1999;341:1949-56

20 Stone GW, Grines CL, Cox DA, et al. Comparison of angioplasty with stenting, with or without abciximab, in acute myocardial infarction. N Engl'J Med 2002;346:957-66.

21 Buchanan JR Jr, Kleinstreuer C. Simulation of particle-hemodynamics in a partially occluded artery segment with implications to the initiation of microemboli and secondary stenoses. J Biomech Eng 1998;120:446-54.

22 Ikeda Y, Handa M, Kawano K, et al. The role of von Willebrand factor and fibrinogen in platelet aggregation under varying shear stress. J Clin Invest 1991;87:1234-40

23 Meier B. Plaque sealing by coronary angioplasty. Heart 2004;90:1395-8.

24 Lemos PA, Saia F, Hofma SH, et al. Short- and long-term clinical benefit of sirolimus-eluting stents compared to conventional bare stents for patients with acute myocardial infarction. J Am Coll Cardiol 2004;43:704-8.

25 McFadden EP, Stabile E, Regar E, et al. Late thrombosis in drug-eluting coronary stents after discontinuation of antiplatelet therapy. Lancet 2004;364:1519-21

26 Liu X, Huang Y, Hanet C, et al. Study of antirestenosis with the BiodivYsio dexamethasone-eluting stent (STRIDE): a first-in-human multicenter pilot trial. Catheter Cardiovasc Interv 2003;60:172-8.

27 Goldstein JA, Demetriou D, Grines CL, et al. Multiple complex coronary plaques in patients with acute myocardial infarction. N Engl J Med 2000;343:915-22.

28 Asakura M, Ueda Y, Yamaguchi O, et al. Extensive development of vulnerable plaques as a pan-coronary process in patients with myocardial infarction: an angioscopic study. J Am Coll Cardiol 2001;37:1284-8. 
29 Schoenhagen $\mathrm{P}$, Stone GW, Nissen SE, et al. Coronary plaque morphology and frequency of ulceration distant from culprit lesions in patients with unstable and stable presentation. Arterioscler Thromb Vasc Biol 2003:23:1895-900.

30 Lee SG, Lee CW, Hong MK, et al. Change of multiple complex coronary plaques in patients with acute myocardial infarction: a study with coronary angiography. Am Heart J 2004; 147:281-6.

31 Schaar JA, de Korte CL, Mastik F, et al. Characterizing vulnerable plaque features with intravascular elastography. Circulation 2003;108:2636-41.

32 Kuchulakanti P, Rha SW, Cheneau E, et al. Identification of "vulnerable plaque" using virtual histology in angiographically benign looking lesion of proximal left anterior descending artery. Cardiovasc Radiat Med 2003;4:225-7.

33 Orlic D, Kajstura J, Chimenti S, et al. Bone marrow cells regenerate infarcted myocardium. Nature 2001;410:701-5.

34 Assmus B, Schachinger V, Teupe C, et al. Transplantation of progenitor cells and regeneration enhancement in acute myocardial infarction (TOPCAREAMI). Circulation 2002; 106:3009-17.

35 Strauer BE, Brehm M, Zeus $\mathrm{T}$, et al. Repair of infarcted myocardium by autologous intracoronary mononuclear bone marrow cell transplantation in humans. Circulation 2002;106:1913-8.

36 Wollert KC, Meyer GP, Lotz J, et al. Intracoronary autologous bone-marrow cell transfer after myocardial infarction: the BOOST randomised controlled clinical trial. Lancet 2004;364:141-8.
37 Mathur A Martin JF. Stem cells and repair of the heart. Lancet 2004;364:183-92.

38 Balsam LB, Wagers AJ, Christensen JL, et al. Haematopoietic stem cells adopt mature haematopoietic fates in ischaemic myocardium. Nature 2004:428:668-73.

39 Murry CE, Soonpaa MH, Reinecke $\mathrm{H}$, et al. Haematopoietic stem cells do not transdifferentiate into cardiac myocytes in myocardial infarcts. Nature 2004:428:664-8.

40 Eagle KA, Goodman SG, Avezum A, et al. Practice variation and missed opportunities for reperfusion in ST-segment-elevation myocardial infarction: findings from the global registry of acute coronary events (GRACE). Lancet 2002;359:373-7.

41 Andersen HR, Nielsen TT, Rasmussen K, et al. A comparison of coronary angioplasty with fibrinolytic therapy in acute myocardial infarction. N Engl J Med 2003;349:733-42.

42 Widimsky P, Budesinsky $T$, Vorac $D$, et al. Long distance transport for primary angioplasty vs immediate thrombolysis in acute myocardial infarction. Final results of the randomized national multicentre trial-PRAGUE-2. Eur Heart $J$ 2003;24:94-104.

43 Aversano T, Aversano LT, Passamani E, et al. Thrombolytic therapy vs primary percutaneous coronary intervention for myocardial infarction in patients presenting to hospitals without on-site cardiac surgery: a randomized controlled trial. JAMA 2002;287:1943-51.

\section{IMAGES IN CARDIOLOGY}

\section{Echinococcal cyst mimicking myocardial infarction}

doi: 10.1136/hrt.2005.062919

A 36 year old woman presented with a history of palpitations and tachycardia over the preceding two weeks. Physical examination was normal and all laboratory tests were unremarkable. However, electrocardiography revealed classical signs of subacute inferior myocardial infarction. Coronary angiography demonstrated normal coronary arteries. A left ventriculogram (panel A) showed a $6 \times 4 \mathrm{~cm}$ cystic lesion with a rim of calcification adherent to the inferior myocardial wall, without impairment of regional wall motion. Echocardiography (panel B) showed an intramyocardial invasion of the cyst into the basal interventricular septum, but no direct communication with cardiac chambers. No additional cysts could be identified. The cardiac

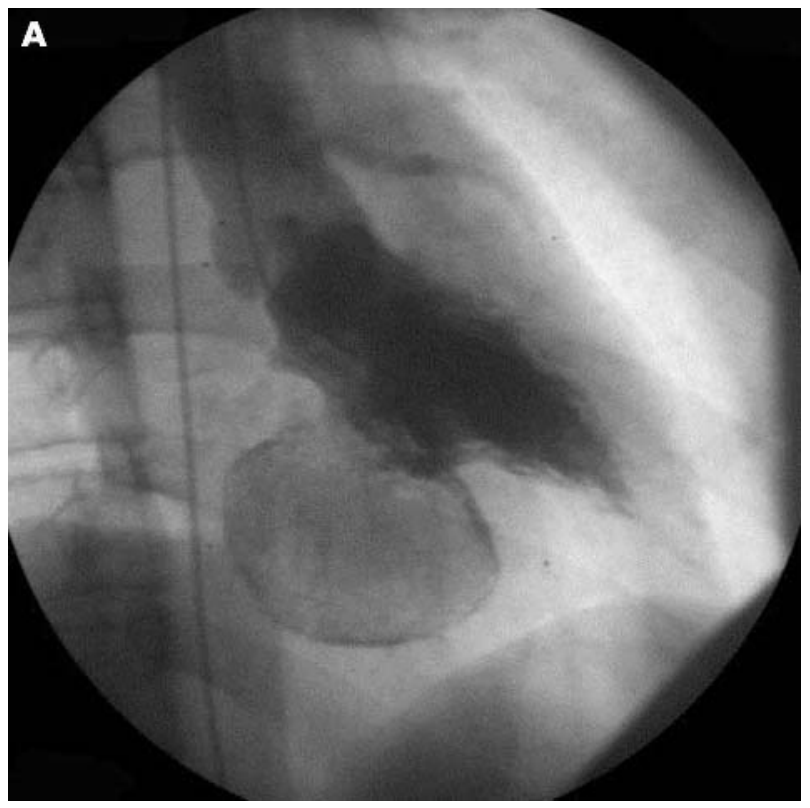

cyst was surgically removed through a median sternotomy. Histopathological analysis was diagnostic for Echinococcus granulosus. The patient's postoperative course was uneventful. She was discharged on albendazole and was doing well one year after the procedure.

Cardiac hydatid disease is rare. When the cysts have an intramyocardial component, the interventricular septum is a common location.

M Derntl

J Bergler-Klein

I M Lang

michael.dernt|@meduniwien.ac.at

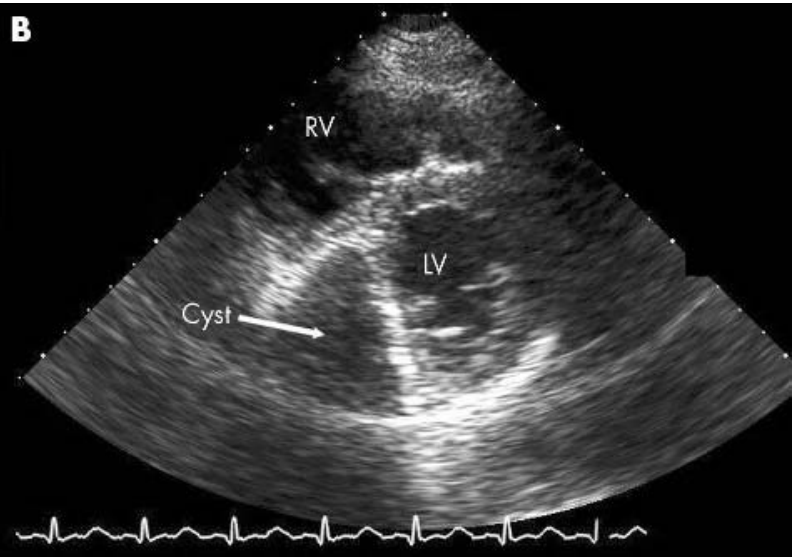

